OPEN ACCESS

Edited by:

Atle M. Bones,

Norwegian University of Science and Technology, Norway

Reviewed by:

Naser A. Anjum,

University of Aveiro, Portugal

Elke Bloem,

Julius Kühn-Institute, Germany

${ }^{*}$ Correspondence:

Philippe Simoneau,

Université d'Angers, INRA, Agrocampus Ouest, UMR 1345 IRHS, SFR 4207 QUASAV, 2 Boulevard Lavoisier, Angers cedex F-49045,

France

simoneau@univ-angers.fr

${ }^{\dagger}$ These authors have contributed equally to this work and should be considered co-first authors.

Specialty section:

This article was submitted to Plant Physiology, a section of the journal Frontiers in Plant Science

Received: 02 April 2015 Accepted: 22 May 2015

Published: 03 June 2015

Citation:

Calmes B, N'Guyen G, Dumur J, Brisach CA, Campion C, lacomi B,

Pigné S, Dias E, Macherel D, Guillemette T and Simoneau P (2015) Glucosinolate-derived isothiocyanates

impact mitochondrial function in fungal cells and elicit an oxidative stress response necessary for growth

recovery.

Front. Plant Sci. 6:414. doi: 10.3389/fpls.2015.00414

\section{Glucosinolate-derived isothiocyanates impact mitochondrial function in fungal cells and elicit an oxidative stress response necessary for growth recovery}

\author{
Benoit Calmes ${ }^{1 \dagger}$, Guillaume N'Guyen ${ }^{1 \dagger}$, Jérome Dumur', Carlos A. Brisach ${ }^{1}$, \\ Claire Campion', Béatrice lacomi², Sandrine Pigné1, Eva Dias ${ }^{1}$, David Macherel', \\ Thomas Guillemette ${ }^{1}$ and Philippe Simoneau ${ }^{1 *}$ \\ 1 Université d'Angers, INRA, Agrocampus Ouest, UMR 1345 IRHS, SFR 4207 QUASAV, Angers, France, ${ }^{2}$ Universitatea de \\ Ştiinţe Agronomice şi Medicină Veterinară Bucureşti, Bucharest, Romania
}

Glucosinolates are brassicaceous secondary metabolites that have long been considered as chemical shields against pathogen invasion. Isothiocyanates (ITCs), are glucosinolate-breakdown products that have negative effects on the growth of various fungal species. We explored the mechanism by which ITCs could cause fungal cell death using Alternaria brassicicola, a specialist Brassica pathogens, as model organism. Exposure of the fungus to ICTs led to a decreased oxygen consumption rate, intracellular accumulation of reactive oxygen species (ROS) and mitochondrialmembrane depolarization. We also found that two major regulators of the response to oxidative stress, i.e., the MAP kinase AbHog1 and the transcription factor AbAP1, were activated in the presence of ICTs. Once activated by ICT-derived ROS, AbAP1 was found to promote the expression of different oxidative-response genes. This response might play a significant role in the protection of the fungus against ICTs as mutants deficient in AbHog1 or AbAP1 were found to be hypersensitive to these metabolites. Moreover, the loss of these genes was accompanied by a significant decrease in aggressiveness on Brassica. We suggest that the robust protection response against ICT-derived oxidative stress might be a key adaptation mechanism for successful infection of host plants by Brassicaceae-specialist necrotrophs like $A$. brassicicola.

Keywords: Alternaria brassicicola, isothiocyanates, oxidative stress, mitochondria, ROS

\section{Introduction}

Plants- as part of their overall defense arsenal- counter pathogen attack by producing de novo antimicrobial phytoalexins (Hammerschmidt, 1999; Ahuja et al., 2012). Besides these newly synthesized metabolites, many plant species also constitutively accumulate compounds referred to as phytoanticipins (Osbourn, 1996) that, due to their high concentration in tissues and potential antimicrobial activities, may also contribute to protecting the plant from pathogen infection. For instance, it has been reported that falcarinol-type polyacetylenes accumulate in carrot leaves at 
concentrations estimated as being 5- to 15-fold higher than $\mathrm{IC}_{50}$ values reported for the fungal pathogen Alternaria dauci (Lecomte et al., 2012). In the same vein, garlic can yield $\sim 2 \mathrm{mg}$ $\mathrm{g}^{-1}$ of the thiosulfinate allicin (Slusarenko et al., 2008) while sevenfold lower quantities are sufficient to inhibit the growth of numerous fungal pathogens (Curtis et al., 2004). Phytoanticipins are a very heterogeneous group of molecules with high structural diversity and the basis of their biocidal activity on fungal cells may not be unique. Indeed, the toxicity of the major oat root saponin avenacin has been associated with its ability to form complexes with fungal membrane sterols, leading to pore formation and loss of membrane integrity (Morrissey and Osbourn, 1999). Similarly, falcarindiol might induce permeabilization of the fungal plasma membrane (Lecomte et al., 2012). By contrast, allicin is readily taken up by fungal cells and, due to its oxidizing properties, might activate apoptosis (Gruhlke et al., 2010).

Members of the Brassicaceae plant family constitutively accumulate high levels (up to $1 \%$ of dry weight) of sulfurcontaining glucosides called glucosinolates (GLS; Fahey et al., 2001). Upon tissue damage (e.g., during pathogen invasion), GLS are enzymatically converted into various breakdown products. Isothiocyanates (ITCs) are one of these myrosinase-catalyzed hydrolytic products (Lambrix et al., 2001) which have been shown to inhibit the growth of various pathogens in vitro (Tierens et al., 2001; Sellam et al., 2007a). In planta, the protective role of GLS against pathogen invasion has yet to be clarified but their catabolism could yield products able to confine fungal infection via their cytotoxicity or through activation of innate immune responses (Bednarek et al., 2009; Clay et al., 2009; Stotz et al., 2011). The cell toxicity of ITCs has mainly been studied on mammal cells due to their antitumor activity. They indeed have the capacity to inhibit the growth of several types of cancer cells by causing apoptotic and autophagic cell death (Cuddihy et al., 2008; Mi et al., 2008; Boreddy et al., 2011). The mechanism by which ITCs causes cell death is not yet fully understood and they may mediate their effects either via direct protein modification or indirectly by disruption of redox homeostasis and increased thiol oxidation (Brown and Hampton, 2011). In line with this, it has been shown that following exposure to ITC, fungal cells displayed a response similar to that elicited during oxidative stress with over-expression of several genes potentially involved in cell protection against oxidative damage (Sellam et al., 2007b).

The aim of this study was to further explore the mechanism by which ITCs exert their toxicity on fungal cells and to study the adaptive response of a Brassicaceae- specific fungus. We used as a model Alternaria brassicicola, the causal agent of the black spot disease of Brassicaceae, to dissect the effects of these glucosinolate-breakdown products on mitochondrial function, intracellular accumulation of reactive oxygen species (ROS) and oxidative stress signaling.

\section{Materials and Methods}

\section{Fungal Strains and Growth Conditions}

The A. brassicicola wild-type (WT) strain Abra43 used in this study has previously been described (Dongo et al., 2009; Joubert et al., 2011). For routine culture, A. brassicicola was grown and maintained on potato dextrose agar (PDA). The method based on micro-scale liquid cultivation (from conidial suspensions) and automated nephelometric recording of growth, followed by extraction of relevant variables (lag time and growth rate), was described by Joubert et al. (2010). To study the susceptibility of fungal strains to ITC, allyl-ITC (AlITC), benzyl-ITC (BzITC), or phenetyl-ITC (PhITC), all purchased from Aldrich Chemical Co. (Milwaukee, WI, USA), were diluted from stock solutions prepared in methanol at the final desired concentrations. Solvent concentrations in controls and assays did not exceed $1 \%(\mathrm{v} / \mathrm{v})$.

\section{RNA Isolation and Expression Analysis by Real-Time Quantitative PCR}

Total RNA was prepared according to the TRIzol reagent protocol (Invitrogen). Additional cleanup and DNase treatment were performed using the Nucleospin RNA II kit (MachereyNagel) according to the manufacturer's protocol. First-strand complementary DNA was synthesized from $5 \mu \mathrm{g}$ of total RNA and used for real-time PCR. Amplification experiments were conducted as previously described (Sellam et al., 2007b) with specific primer combinations (Supplementary Table S1). The relative quantification analysis was performed using the comparative $\Delta \Delta \mathrm{Ct}$ method as described by Winer et al. (1999). To evaluate the gene expression level, the results were normalized using $\mathrm{Ct}$ values obtained from tubulin cDNA amplifications run on the same plate.

\section{Generation of Targeted Gene Replacement Constructs and Fungal Transformation}

The construction of the $\Delta a b h o g 1$ strain was previously described by Joubert et al. (2011). To construct the $\Delta a b a p 1$ mutant strains, a gene replacement cassette was generated using the double-joint PCR procedure ( $\mathrm{Yu}$ et al., 2004). The selectable marker inserted in the PCR constructs corresponded to the Hph gene cassette (1436 bp) from pCB1636 (Sweigard et al., 1995) which confers resistance to hygromycin $\mathrm{B}$. The sets of primers used to amplify the $5^{\prime}$ and $3^{\prime}$ flanking regions of the targeted gene are presented in Supplementary Table s1. The doublejoint final PCR products were used to transform A. brassicicola Abra43 protoplasts as described by Cho et al. (2006). Potential transformants were prescreened by PCR with relevant primer combinations (Supplementary Table S1) to confirm integration of the replacement cassette at the targeted locus. Two putative gene replacement mutants were further purified by three rounds of single-spore isolation and then confirmed by PCR and Southern blot analysis. Genomic DNA extraction and Southern blot analysis were conducted as previously described by Joubert et al. (2011).

\section{Generation of Fusion Protein Constructs}

The AbHog1 and AbAp1 C-terminal GFP fusion constructs were generated by fusion PCR as described in Pochon et al. (2013). Using A. brassicicola genomic DNA as template, the respective ORFs and $3^{\prime}$ flanking regions were amplified with relevant primer combinations (Supplementary Table S1). In parallel, a fragment containing the sGFP and Hyg B cassettes 
were amplified from the plasmid pCT74 (Lorang et al., 2001) and $\mathrm{pCB} 1636$, respectively. The resulting PCR fragments were mixed and subjected to second fusion PCR. A linker containing three glycine residues was introduced at the $3^{\prime}$ end of the respective ORFs to replace the stop codons. The final PCR products were transformed either in the A. brassicicola WT strain Abra43 or in a derivative strain constitutively expressing mCherry-NLS from plasmid pBV579 (Khang et al., 2010) under control of the ToxA promoter from pCT74. Transformants with the expected genetic integration events were identified by PCR.

\section{Infection Assays}

For plant infection assays on Brassica oleracea plants (var. Bartolo), $5 \mu \mathrm{L}$ drops of $A$. brassicicola conidia suspension $\left(10^{5}\right.$ conidia/mL in water) with or without diphenyleneiodonium (DPI; $0.4 \mu \mathrm{M}$ ) dissolved in DMSO were inoculated on leaves from 5 weeks-old plants. Inocula were symmetrically deposited on the left and right sides of the central vein. The plants were then maintained under saturating humidity (100\% relative humidity). Symptoms were monitored at 7 days post-inoculation (dpi). Ten leaves were inoculated per condition and the experiment was repeated twice.

\section{Western Blot Analysis}

The phosphorylation status of Hog1-related MAPK in A. brassicicola was studied by western blot using antibodies directed against dually phosphorylated forms of p38 MAPK (Cell Signaling Technology, Beverly, MA, USA). Total Hog1 proteins were detected using anti-Hog1 antibodies (Santa Cruz Biotechnology). Samples for study of the Hog1-related protein phosphorylation status were prepared from mycelia obtained by growing conidial suspensions at $25^{\circ} \mathrm{C}$ for $24 \mathrm{~h}$ in PDB $\left(2 \times 10^{5}\right.$ conidia $/ \mathrm{mL}$ ) and then exposed to $2.5 \mathrm{mM}$ AlITC. Mycelia were collected by filtration on filter paper, ground with a mortar and pestle to a fine powder under liquid nitrogen and homogenized in ice-chilled buffer containing protease and phosphatase inhibitors [50 mM Na phosphate, pH 7.4, $1 \mathrm{mM}$ EDTA, 5\% (v/v) glycerol, $1 \mathrm{mM}$ PMSF, $50 \mathrm{mM} \mathrm{NaF}, 5 \mathrm{mM}$ Na pyrophosphate, $0.1 \mathrm{mM} \mathrm{Na}$ vanadate, $10 \mathrm{mM} b$-glycerophosphate]. Extracts were centrifuged at $10000 \mathrm{~g}$ for $10 \mathrm{~min}$, and the resulting supernatants were stored at $-80^{\circ} \mathrm{C}$ until use. The protein concentration in the extracts was calculated using a BCA protein assay reagent (Pierce, Rockford, IL, USA). Equal quantities $(5 \mu \mathrm{g})$ of protein samples were loaded on $10 \%$ polyacrylamide gels and blotted onto nitrocellulose membranes (Schleicher and Schuell, Dassel, Germany). For each treatment, protein samples were prepared from at least three independent cultures and each sample was used to prepare at least three series of duplicated blots. Antibody binding was visualized using an ECL Plus Western blotting detection reagent (Amersham Biosciences, Buckinghamshire, UK) after binding of a horseradish peroxidase-conjugated secondary antibody.

\section{Intracellular Detection of Oxidative Products}

Intracellular ROS were detected on $16 \mathrm{~h}$-old germinating conidia after exposure to $2.5 \mathrm{mM} \mathrm{Al}-\mathrm{ITC}$ or $1 \%(\mathrm{v} / \mathrm{v})$ methanol for $1 \mathrm{~h}$.
After treatment, the incubation mixtures were mixed with $2^{\prime}, 7^{\prime}$ dichlorodihydrofluorescein diacetate $\left(\mathrm{H}_{2}\right.$ DCF-DA, Molecular Probes) or dihydroethidium (DHE, Molecular Probes) solutions (1 $\mu \mathrm{M}$ final concentration) and observations were performed under a fluorescent microscope (Leica DM4500) with the following filter combinations: 546 and $605 \mathrm{~nm}$ excitation and emission wavelengths respectively for DHE or 480 and $527 \mathrm{~nm}$ excitation and emission wavelengths respectively for $\mathrm{H}_{2}$ DCF-DA.

\section{Measurement of Mitochondrial Transmembrane Potential}

To measure the change in mitochondrial transmembrane potential $(\Delta \Psi \mathrm{m}), 16 \mathrm{~h}$-old germinating conidia were treated for $10 \mathrm{~min}$ with $2.5 \mathrm{mM}$ Al-ITC or $1 \%(\mathrm{v} / \mathrm{v})$ methanol and then the cationic lipophilic dye 5,5', $6^{\prime}$-tetrachloro $1,1^{\prime}, 3,3^{\prime}$ tetraethylbenzimidazolylcarbocyanine iodide (JC-1; Invitrogen) was added ( $2 \mu \mathrm{g} / \mathrm{mL}$ final concentration), and the mixture was further incubated for $10 \mathrm{~min}$ in the dark. Fungal mats were then collected by filtration, washed thoroughly with PDB and observed under a fluorescent microscope with the following filter combinations: 546 and $605 \mathrm{~nm}$ excitation and emission wavelengths for the visualization of JC-1 aggregates in mitochondrial matrix, or 480 and $527 \mathrm{~nm}$ excitation and emission wavelengths for visualization of monomers in the cytoplasm of cells with depolarized mitochondria. To calculate the green/red fluorescence ratio of JC-1, images were all acquired with the same settings and exported in the software Image ${ }^{1}$ to quantify pixel numbers corresponding to green and red fluorescence.

\section{Oxygen Consumption Rate Measurement}

The respiratory activity was measured using the MitoXpress (Luxcel Biosciences, Cork, Ireland) fluorescent probe. Conidia $\left(10^{4} / \mathrm{mL}\right)$ of WT $A b r a 43$ were germinated for $14 \mathrm{~h}$ at $25^{\circ} \mathrm{C}$ in PDB medium, in the wells of a 96-well plate, and growth was monitored with nephelometry. The medium was then removed by aspiration and replaced with $150 \mu \mathrm{L}$ of diluted $(10 \% \mathrm{v} / \mathrm{v})$ PDB medium containing $100 \mathrm{nM}$ MitoXPress, and overlaid with $100 \mu \mathrm{L}$ mineral oil. Inhibitors (Al-ITC or KCN) were added at this stage. Oxygen depletion in the medium was estimated from the increase in the fluorescence lifetime (LT) of the probe using a Fluostar Omega plate spectrofluorometer equipped with a time-resolved fluorescence head (BMG LABTECH GmbH, Ortenberg, Germany). At each time point, fluorescence relative units (340 nm excitation, $605-705 \mathrm{~nm}$ emission) were recorded (50 flashes) for $30 \mu \mathrm{s}$ after 30 and $70 \mu \mathrm{s}$, and the probe LT was calculated from the fluorescence intensity ratio at 30 and $70 \mu$ s delays as follows: $\mathrm{LT}=(70-30) / \mathrm{Ln}(\mathrm{W} 1 / \mathrm{W} 2)$ where 70 is the W2 delay time $(70 \mu \mathrm{s})$ and 30 is the W1 delay time $(30 \mu \mathrm{s}) . \mathrm{W} 1$ is the RFU signal measured after the W1 delay, W2 is the RFU signal measured after the W2 delay. MitoXpress LT data were analyzed using the MARS data analysis software version 2.30 (BMG LABTECH GmbH, Ortenberg, Germany). To assess the impact of Al-ITC or KCN on hyphae respiration, the slopes of LT were measured 60-90 min after

${ }^{1}$ http://rsb.info.nih.gov/ij/ 
the addition of the compounds, and compared to those of the control.

\section{Results}

\section{Susceptibility of $A$. brassicicola to ITC}

Analyses of growth curves in liquid medium supplemented with various concentrations of Al-ITC, Bz-ITC, or Ph-ITC were used to assess the susceptibility of the WT A. brassicicola strain Abra43 to different ICTs. Areas under the curves were used to estimate the growth inhibitory effect of each compound and calculate the $\mathrm{IC}_{50}$. As shown in Figure 1, maximal and minimal inhibitions were obtained with Al-ITC (IC $502.9 \mathrm{mM})$ and Bz-ITC (IC 50 $6.0 \mathrm{mM}$ ), respectively. An intermediate effect was observed with Ph-ITC ( IC $_{50} 4.2 \mathrm{mM}$ ). Due to the higher toxic effect of Al-ITC on A. brassicicola, most of the experiments were then performed using this compound. Careful examination of the growth curves revealed that the sensitivity of $A$. brassicicola to the different ITCs was clearly explained by a delayed entry into the log phase (i.e., increased lag times) while its maximum growth rate was only slightly affected.

\section{ITC Induces Intracellular ROS Accumulation}

Reactive oxygen species generation of fungal cells exposed to $2.5 \mathrm{mM}$ Al-ITC was monitored by using $\mathrm{H}_{2}$ DCFDA, a cell-permeable general ROS indicator that penetrates live cells but does not fluoresce unless oxidized by ROS. Intense green fluorescence was distributed along the hyphae in ITCtreated sample, indicating that ROS was generated in the cells. No ROS- specific signals were detected in control hyphae (Figure 2). This result was confirmed after visualization of ROS production by incubating cells with DHE, a non-fluorescent compound which, upon reacting with superoxide, is converted to a fluorescent derivative. These observations demonstrated that ITC promoted intracellular ROS production. Similar observations were obtained after exposure to $\mathrm{Bz}$ - and $\mathrm{Ph}-\mathrm{ITC}$ (not shown).

\section{Hog1 MAP Kinase Activated Upon Exposure to ITC}

In some fungal species the MAP kinase Hog1 has been shown to be activated by ROS and actually mediate oxidative stress responses (Moye-Rowley, 2003; Aguirre et al., 2006; Lin and Chung, 2010). We thus explored the phosphorylation status of AbHog1 in A. brassicicola after exposure to Al-ITC using a western blot approach. A. brassicicola cells were grown in liquid medium, exposed for various times to Al-ITC and then harvested for total protein extraction. Immunoblot analysis using anti-phospho-p38 antibodies revealed that increased phosphorylation of the AbHog1 MAPK occurred as early as 5 min after exposure (Figure 3). Longer exposures resulted in a decreased signal and after $1 \mathrm{~h}$ over-phosphorylation of AbHog1 compared to the control was no longer observed. In response to various stresses, the activated Hog1 protein accumulated in the nucleus (Reiser et al., 1999). To test whether this phenomenon also occurs in A. brassicicola after exposure

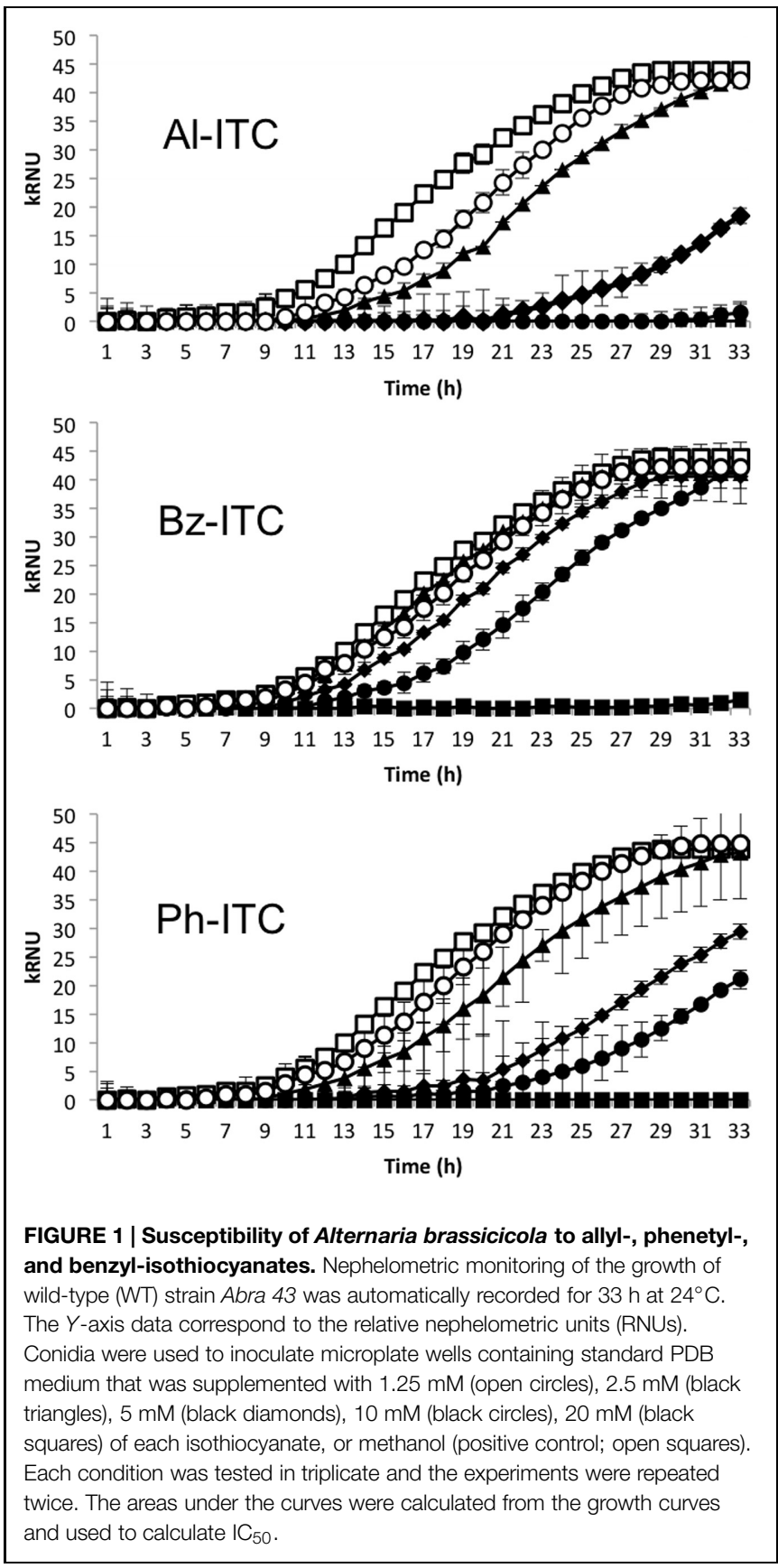

to ITC, a strain constitutively expressing the mCherry-NLS protein from the ToxA promoter and expressing a Hog1::eGFP fusion protein from the AbHogl promoter was constructed. Under control conditions this strain showed green fluorescence signals within the hyphae which did not co-localize with the red labeled fluorescence observed in nuclei (Figure 4). However, when cells were exposed for $20 \mathrm{~min}$ to $2.5 \mathrm{mM}$ ITC dense green fluorescent spots were observed along the hyphae. Their distribution matched the labeled nuclei, thus demonstrating nuclear migration of the MAP kinase in ITCtreated cells. 


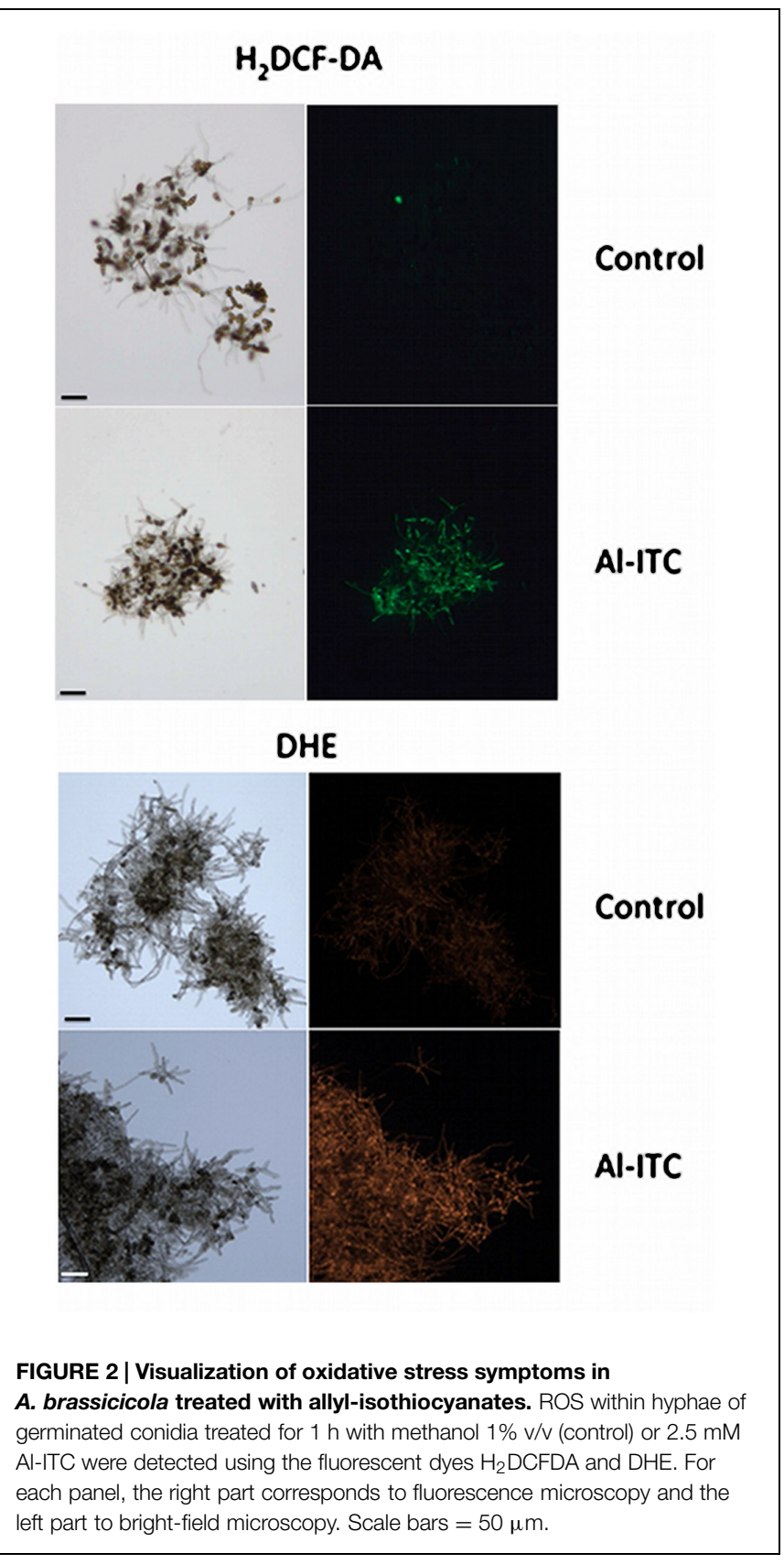

\section{AbAP1 Transcription Factor Activated and Controlled Oxidative Response Gene Expression after ITC Exposure}

Saccharomyces cerevisiae YAP1 protein and other AP1-like fungal orthologs are considered as major oxidative stress response transcription factors (TFs). An ortholog of this protein was identified as AB04817.1 via BLAST analyses in the A. brassicicola automatically annotated genome database ${ }^{2}$ and named AbAP1. Analysis of AbAP1 showed the expected conserved bZIP DNAbinding, nuclear localization, $\mathrm{N}$-terminal and carboxyl terminal

${ }^{2}$ http://genome.jgi-psf.org/Altbr1

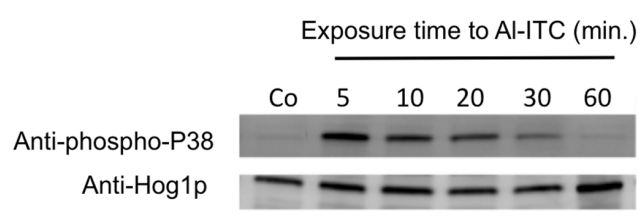

FIGURE 3 | Phosphorylation of the Hog1-like MAPK in A. brassicicola after exposure to allyl-isothiocyanate. Germinated conidia from the WT strain (Abra43) were grown for $24 \mathrm{~h}$ in PDB and exposed to $2.5 \mathrm{mM} \mathrm{Al-ITC}$ for 5-60 min. Control (Co) cultures were supplemented with methanol alone. Total protein extracts, prepared from the harvested mycelia, were analyzed by SDS-PAGE and blotting with either anti-Hog1 C-terminus antibody or anti-dually phosphorylated p38 antibody.

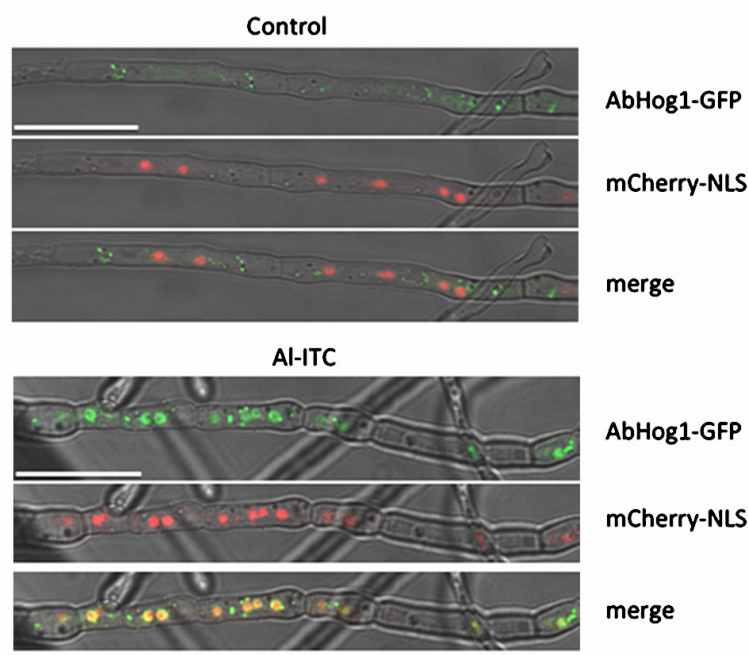

FIGURE 4 | Isothiocyanate-induced nuclear accumulation of the AbHog1-GFP fusion protein. Double-labeled strains expressing AbHog1-GFP and mCherry-NLS were exposed to either methanol (control) or $2.5 \mathrm{mM}$ Allyl-ITC for $20 \mathrm{~min}$. Co-localization analyses were examined using confocal microscopy. Bars $=25 \mu \mathrm{m}$.

cysteine-rich domains (Supplementary Figure S1). AP1-like proteins behave like redox sensors that localize inside the nucleus upon exposure to ROS and then regulate the expression of a large set of genes including oxidative response genes (Lee et al., 1999; Lev et al., 2005; Asano et al., 2007; Temme and Tudzynski, 2009; Znaidi et al., 2009; Takahashi et al., 2010; Guo et al., 2011; Tian et al., 2011; Montibus et al., 2013). To determine whether this is also true for AbAP1 in response to ITC, we generated a strain co-expressing a C-terminal AbAP1::eGFP fusion protein and the mCherry-NLS protein. As shown in Figure 5, in the absence of oxidative stress, green fluorescence was distributed throughout the hyphae, suggesting cytoplasmic TF accumulation. By contrast after 20 min exposure to ITC, green fluorescence was concentrated in discrete spots co-localizing with the mCherry fluorescence signals indicating nuclear localization of AbAP1::eGFP in response to ITC. 


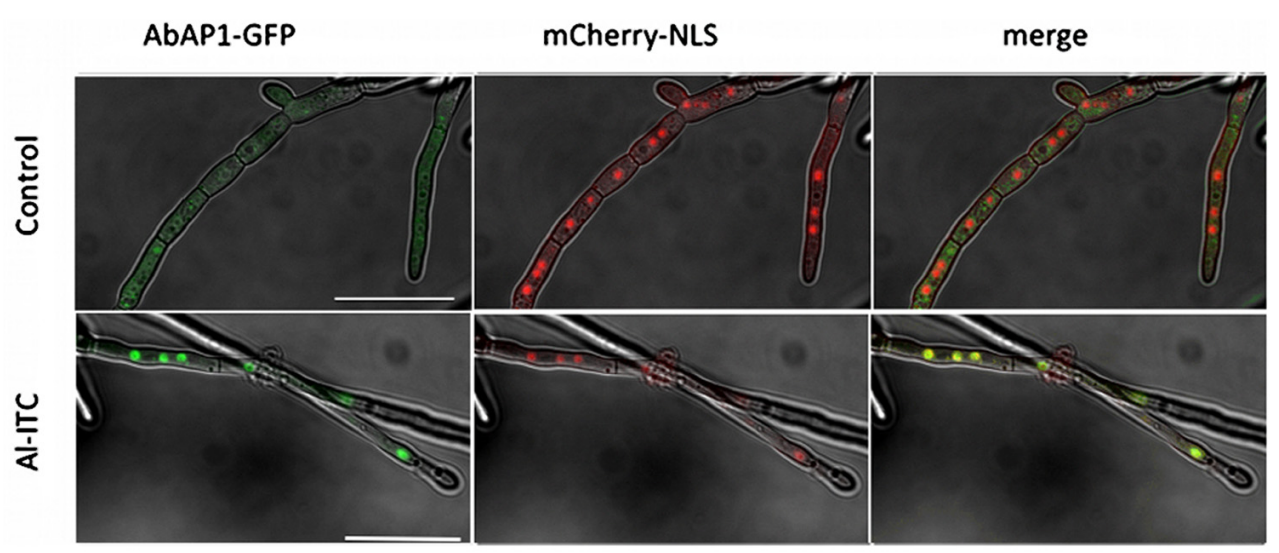

FIGURE 5 | Isothiocyanate-induced nuclear accumulation of the AbAP1-GFP fusion protein. Double-labeled strains expressing AbAP1-GFP and mCherry-NLS were exposed to either methanol (control) or $2.5 \mathrm{mM}$ Allyl-ITC for $20 \mathrm{~min}$. Co-localization was examined using confocal microscopy. Bars $=25 \mu \mathrm{m}$.

TABLE 1 | Expression of oxidative stress response genes in the wild-type (WT) and $\Delta a b a p 1$ strains after 20 min of exposure to Al-ITC.

\begin{tabular}{|c|c|c|c|c|}
\hline $\begin{array}{l}\text { Target sequence } \\
\text { (GenBank acc. \#) }\end{array}$ & PotentialFunction ${ }^{a}$ & $\begin{array}{l}\text { Fold induction } \\
\text { in WT }( \pm S D)^{b}\end{array}$ & $\begin{array}{l}\text { Fold induction in } \Delta \text { abap1 } \\
\text { /Fold induction in WT }\end{array}$ & $p$-Value (t-test) \\
\hline A3H11 (DY542661) & $\operatorname{TRX}$ & $26.2 \pm 4.6$ & 0.07 & 8E-04 \\
\hline A2G8 (DY542662) & $\mathrm{TRX}$ & $107.6 \pm 24$ & 0.08 & 0.002 \\
\hline A3G5 (DY542663) & TRX & $77.4 \pm 23.4$ & 0.25 & 0.013 \\
\hline A1B12 (DY542664) & $\mathrm{TRX}$ & $116.2 \pm 13$ & 0.04 & 1E-04 \\
\hline A4D11 (DY542665) & TRR & $12.8 \pm 0.88$ & 0.22 & 1E-04 \\
\hline A2H9 (DY542667) & QOX & $22.44 \pm 2.6$ & 0.24 & 0.002 \\
\hline A3D2 (DY5426674) & CytP450 & $8.39 \pm 1.9$ & 0.47 & 0.02 \\
\hline A3D10 (DY542658) & GPX & $10.36 \pm 0.8$ & 0.17 & 4.9E-05 \\
\hline A2F9 (DY542659) & GCS & $25.95 \pm 6.1$ & 0.05 & 0.002 \\
\hline A2H5 (DY542653) & GST & $39.23 \pm 11.6$ & 0.19 & 0.009 \\
\hline A2C10 (DY542656) & GST & $21.57 \pm 1.27$ & 0.09 & 1.9E-05 \\
\hline A1F1 (DY542654) & GST & $9.01 \pm 2.2$ & 0.77 & 0.165 \\
\hline A2C1 (DY542655) & GST & $12.78 \pm 2.5$ & 0.04 & 0.001 \\
\hline A4D12 (DY542657) & GST & $8.74 \pm 1.27$ & 0.12 & 4E-04 \\
\hline
\end{tabular}

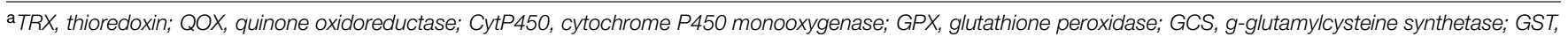

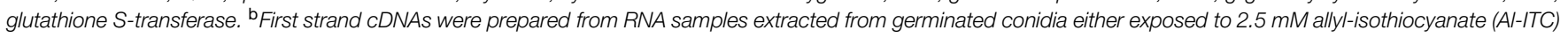

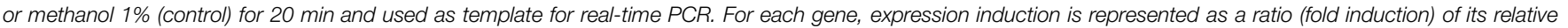

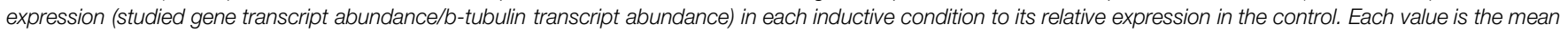
of two independent experiments with the WT strain and two independent $\Delta$ abap1 mutants, each with three replicates.

We then checked whether oxidative stress response genes, previously reported as overexpressed in A. brassicicola exposed to ITC (Sellam et al., 2007b), required AP1 for induction. Mutants deficient in this TF were generated by gene replacement and exposed to ITC. The expression levels of a set of 14 genes were then compared to those measured in the same conditions for the parental WT strain. As expected all the selected genes were strongly overexpressed in the Abra 43 WT strain after 20 min of exposure to Al-ITC (Table 1). By contrast, the majority of the selected genes (11/14) were no longer induced, or induced at a significantly lower level $(p<0.01)$ under the same conditions in the $\triangle a b a p 1$ mutant. The expression of only three genes encoding a putative thioredoxin, a cytochrome P450 monooxygenase and a glutathione $S$-transferase was found independent of AbAP1 for induction.

\section{A. brassicicola Strains with an Impaired Oxidative-Stress Response are Hypersensitive to ITC}

Two $\Delta a b h o g 1$ mutants (Joubert et al., 2011) and two $\Delta a b a p 1$ mutants were tested for their susceptibility to different oxidizing compounds. Nephelometric monitoring of the initial growth stages was used to assess the effects of $\mathrm{H}_{2} \mathrm{O}_{2}$, menadione, and various ITCs (Al-, Bz-, and Ph-ITC) on the fungus. As independent strains behaved similarly for each genotype, the percentage of growth inhibition and growth curves shown in Figures 6 and 7, respectively, correspond to means of values obtained for individuals carrying the same mutation. Under control conditions (PDB medium), $\Delta a b h o g 1$ mutant growth was slower than that of the WT and $\Delta a b a p 1$ strains (Figure 7). All mutants were found to be more 


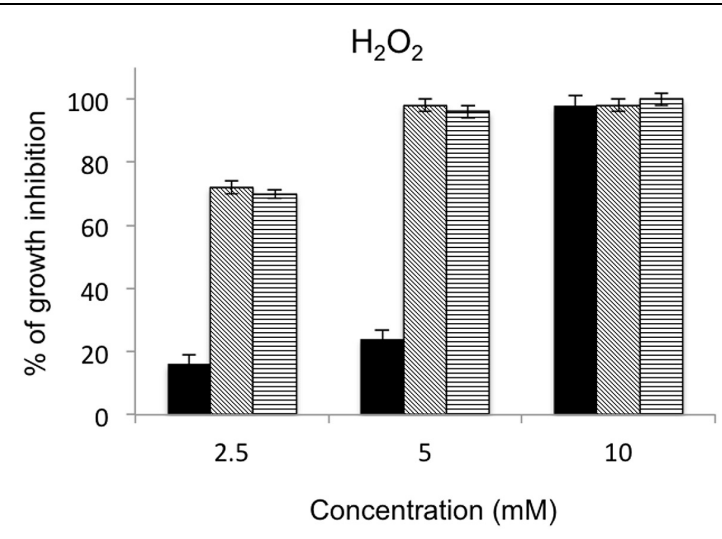

FIGURE 6 | Susceptibility of $A$. brassicicola wild-type (black bars), $\Delta$ abhog1 (hatched bars) and $\Delta a b a p 1$ (stripped bars) strains to oxidative stress. Conidia of each genotype were used to inoculate microplate wells containing standard PDB medium supplemented with various concentrations of $\mathrm{H}_{2} \mathrm{O}_{2}$ or menadione. Nephelometric

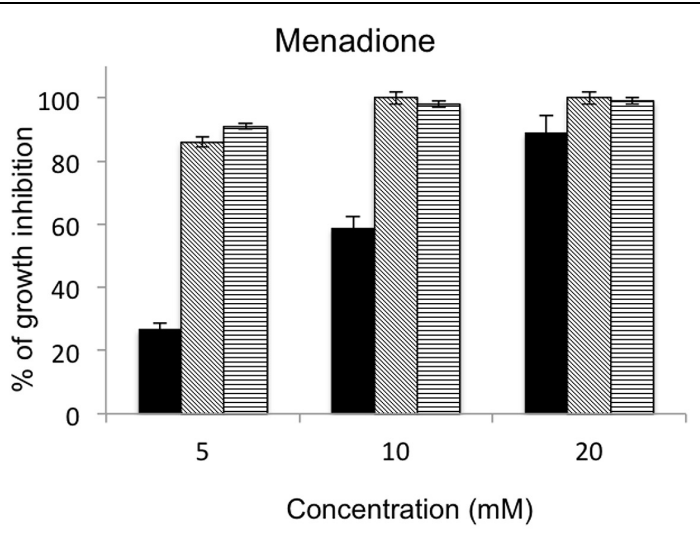

monitoring of growth was automatically recorded for $33 \mathrm{~h}$ at $24^{\circ} \mathrm{C}$. Each condition was tested in triplicate and the experiments were repeated twice. The areas under the curves were used to calculate de percentages of inhibition for each treatment compared to control growth curves.

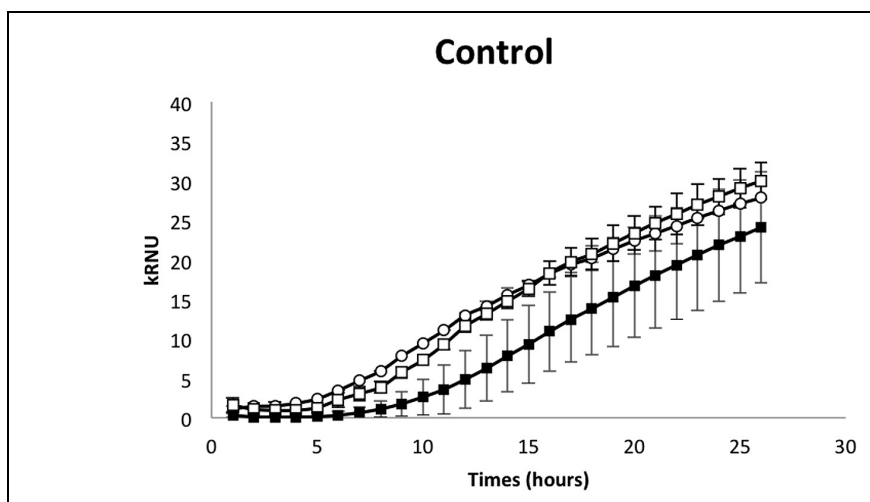

Bz-ITC

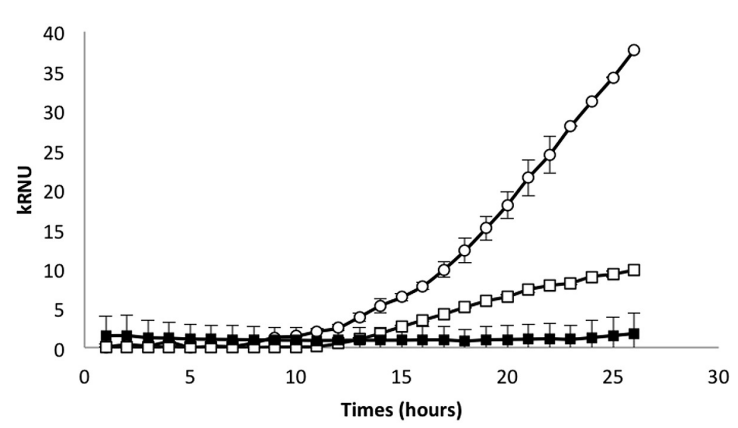

FIGURE 7 | Susceptibility of $A$. brassicicola WT (open circle), $\Delta a b h o g 1$ (black square) and $\Delta$ abap1 (open square) to allyl-, phenetyl-, and benzyl-isothiocyanates. Nephelometric monitoring of growth was

automatically recorded for $27 \mathrm{~h}$ at $24^{\circ} \mathrm{C}$. The $Y$-axis data correspond to RNUs.

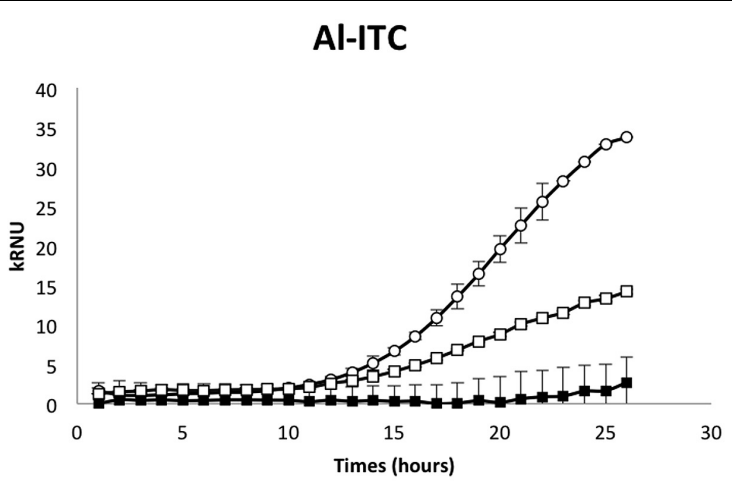

Ph-ITC

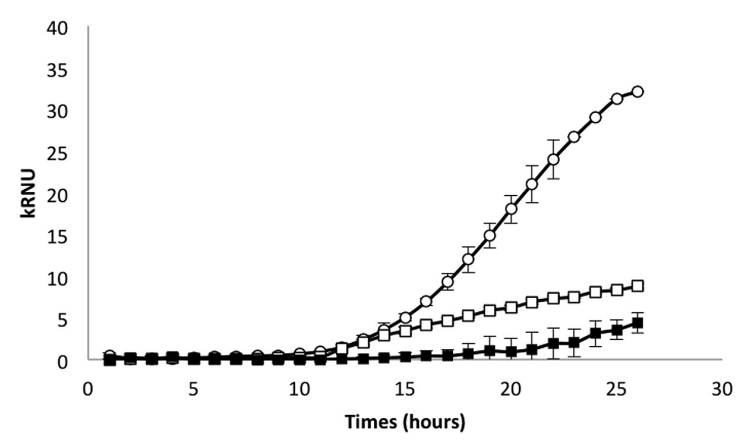

Conidia were used to inoculate microplate wells containing standard PDB medium supplemented with either $5 \mathrm{mM} \mathrm{Al-ITC}$ or $5 \mathrm{mM} \mathrm{Bz-ITC}$ or $5 \mathrm{mM}$ Ph-ITC or methanol (control). Each condition was tested in triplicate and the experiments were repeated twice. susceptible than the WT to the different treatments; $\Delta a b a p 1$ and $\Delta a b h o g 1$ mutants were highly susceptible to menadione and moderately susceptible to $\mathrm{H}_{2} \mathrm{O}_{2}$ (Figure 6). Exposure to all the tested ITCs dramatically affected $\Delta a b h o g 1$ mutant growth and to a lesser extent that of $\Delta a b a p 1$ mutants (Figure 7).

\section{ITC Disrupts the Mitochondrial Membrane Potential in Fungal Cells and Decreases Oxygen Consumption Rate}

Various studies on human cells have assessed the effects of ICTs on mitochondria, and revealed that dissipation of the mitochondrial membrane potential $(\Delta \Psi)$ occurs upon exposure. 
We tested whether a similar effect could be observed in fungal cells exposed to ITC using JC-1 dye. This cationic dye accumulates in the mitochondrial matrix as a function of the membrane potential. At high concentrations (reflecting a high $\Delta \Psi)$ JC-1 forms aggregates displaying orange-red fluorescence. At lower concentrations, when $\Delta \Psi$ decrease or collapse, JC1 is present as monomers exhibiting a green fluorescence. The green/red fluorescence ratio of $\mathrm{JC}-1$ is therefore an indicator of the mitochondrial membrane potential, and thus of mitochondrial function. After short-term exposure (10 min) to $2.5 \mathrm{mM}$ Al-ITC, there was an increase in green fluorescence indicative of a decrease in mitochondrial $\Delta \Psi$ (Figure 8). The mean green/red fluorescence ratio of the probe increased from $0.113 \pm 0.037$ in the control to $0.474 \pm 0.021$ after treatment. Under similar exposure conditions, monomeric JC1 - associated green fluorescence in ITC-treated cells was more pronounced in the $\Delta a b a p 1$ strain than in the WT with the mean green/red fluorescence ratio of the probe reaching $0.646 \pm 0.095$ (Figure 8C). These alterations in $\Delta \Psi$ indicate that Al-ITC can rapidly induce modifications in mitochondrial functions and cellular energy metabolism. In order to further assess the impact of the compound on fungal respiration, oxygen consumption of hyphae was measured after 60 min exposure to Al-ITC using a water-soluble oxygensensitive fluorescent probe. In comparison to the untreated (solvent only) control, Al-ITC clearly inhibited respiration of the WT cells in a dose-dependent manner, reaching $40 \%$ inhibition at $10 \mathrm{mM}$ (Figure 9). Cyanide, a strong inhibitor of cytochrome oxidase, induced $85 \%$ inhibition of respiration, suggesting low activity of the alternative oxidase in the WT strain (Figure 9).

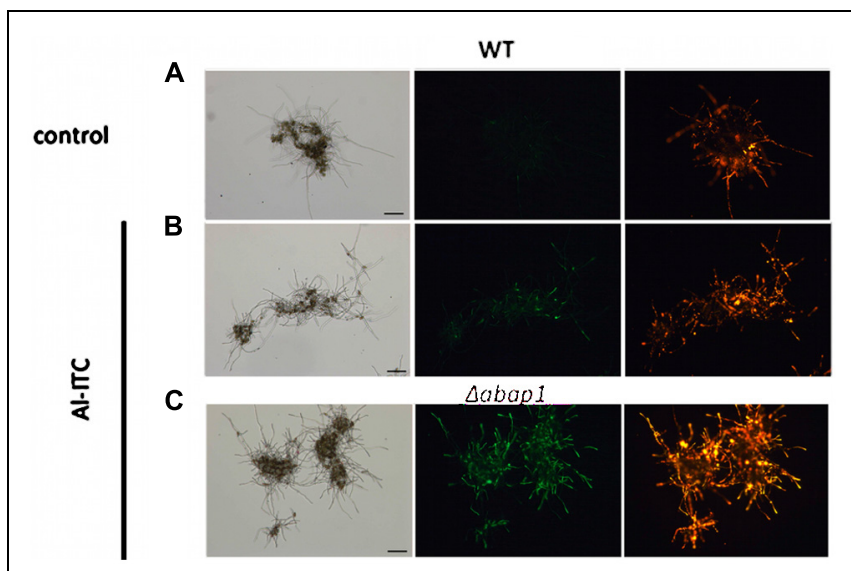

FIGURE 8 | Effect of allyl-isothiocyanate on the mitochondrial membrane potential of $\boldsymbol{A}$. brassicicola cells. The mitochondrial membrane potential was assessed within hyphae of germinated conidia from the WT strain Abra43 $(\mathbf{A}, \mathbf{B})$ or the $\Delta a b a p 1$ mutant $(\mathbf{C})$ using the fluorescent potentiometric dye JC-1 after 10 min treatment with methanol $1 \% \mathrm{~V} / \mathrm{V}$ (A, control) or $2.5 \mathrm{mM} \mathrm{Al-ITC}(\mathbf{B}, \mathbf{C})$. For panels $(\mathbf{A}, \mathbf{B}, \mathbf{C})$ the left part corresponds to bright-field microscopy and the right parts to fluorescence microscopy. Red signals correspond to cells containing mitochondria with high membrane potential and green signals represent mitochondria with low membrane potential. Scale bars $=50 \mu \mathrm{m}$.

\section{Mutants Defective in the Oxidative Stress Response have Decreased Aggressiveness on Glucosinolate Accumulating Host Plants}

To test the effects of targeted $A b H o g 1$ and $A b A P 1$ gene knockout on pathogenicity, $B$. oleracea leaves were inoculated with drops of conidia suspension $\left(10^{5}\right.$ conidia $\left./ \mathrm{mL}\right)$ with or without the NADPH oxidase inhibitor DPI $(0.4 \mu \mathrm{M})$. Necrotic areas were measured at $7 \mathrm{dpi}$. As shown in Figure 10, in the absence of DPI the virulence of $\Delta a b h o g 1$ and $\Delta a b a p 1$ mutants was significantly decreased compared to the WT strain. When the NADPH oxidase inhibitor was applied with the fungal inoculum significantly smaller necrotic areas were observed for all tested genotypes. At the selected concentration, DPI had no negative effect on conidia germination and hyphal growth. In such conditions, i.e., when oxidative stress generated in planta was mainly due to glucosinolate-derived ITCs, the $\Delta a b a p 1 \Delta$ and the $\Delta a b h o g 1$ mutants were almost completely non-virulent.

\section{Discussion}

Glucosinolates are a class of S- and $\mathrm{N}$ - containing secondary metabolites that are found in only 15 botanical families of the Capparales order and are very abundant in the Brassicaceae family (Fahey et al., 2001). They are thought to play a variety of roles in plant defense responses. Indeed, it has been repeatedly reported that GLS-derived ICTs have a negative effect on the growth of various fungal species including specialist Brassica pathogens (Manici et al., 1997; Smolinska et al., 2003; Sellam et al., 2007a). It was previously reported that the inhibitory effect of ITCs depends on their type, and aliphatic ITCs usually have stronger in vitro inhibitory effects on fungi than aromatic ITCs (Smolinska et al., 2003). Moreover, it was shown that Arabidopsis thaliana mutants with low aliphatic GLS content had decreased ability to defend themselves against necrotrophic fungi (Stotz et al., 2011; Buxdorf et al., 2013). In line with these studies, we showed here that ITCs, at concentrations in the millimolar range, significantly slowed down the development of A. brassicicola, with allyl-ITC being much more efficient than phenetyl- and benzyl-ITC. These differences might reflect differential accumulation of ITCs in the fungal cell due to the side-chain structures or different mechanisms of action.

Many studies have explored the cellular targets of ITCs in mammalian cells that might explain their chemoprotective and anticarcinogenic properties (for recent reviews see Zhang, 2010; Navarro et al., 2011). By contrast, the mechanism by which they exert their toxicity on fungal cells has been poorly documented. Sellam et al. (2007b) conducted a transcriptomic analysis of the response of $A$. brassicicola to Al-ITC exposure. Among the overexpressed genes, more than one third could be considered as related to an adaptive response to cellular oxidative stress suggesting that the ITC mediates redox dysregulation in the fungal cell. Increased ITC-induced ROS accumulation was indeed demonstrated here using DHE and $\mathrm{H}_{2}$ DCFDA probes. This observation corroborates the observed effects of ITC on many mammal cell lines such as human lung (Wu et al., 2010; Liu 


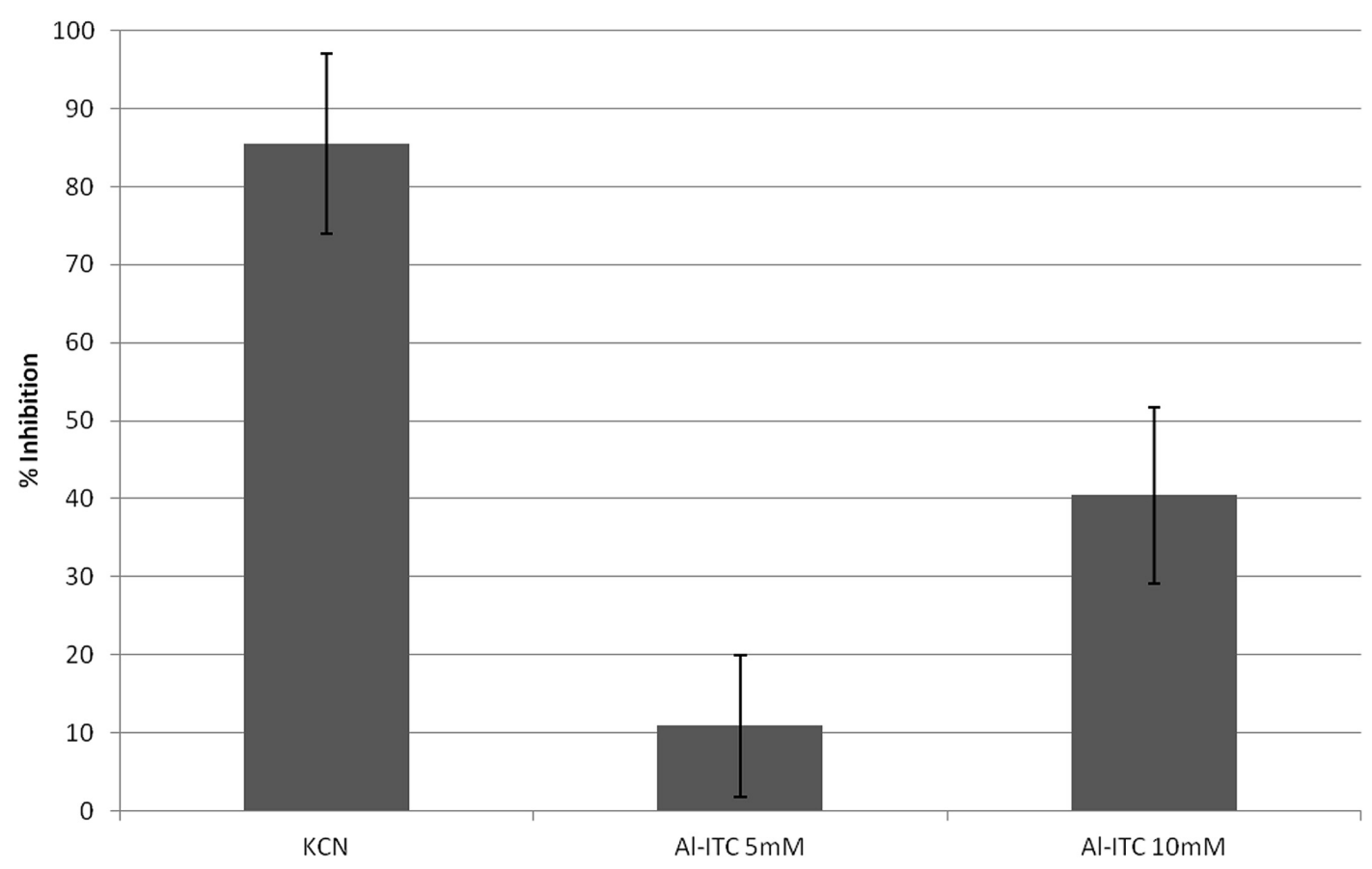

FIGURE 9 | Effect of Al-ITC on A. brassicicola hyphae respiration. The graph shows the inhibitory effects (\% of the control) of ITC or KCN on the respiration rate of $14 \mathrm{~h}$ germinated conidia, measured 60 min after the addition of the compounds. SD is indicated.

et al., 2012), breast (Xiao et al., 2008), and prostate (Xiao et al., 2010) cancer cells. In the latter study, it was demonstrated using the MitoSOX Red probe that ROS generation by ITC in cancer cells was mitochondria-derived. MitoSOX Red was previously reported to be a useful intracellular ROS indicator in different fungal species such as Mycosphaerella graminicola and S. cerevisiae (Batova et al., 2010; Scalliet et al., 2012). However, we did not succeed in localizing ROS accumulated in ITCtreated $A$. brassicicola cells using this fluorescent compound probably due to its weak penetration across the fungal cellwalls. Using JC-1 dye we clearly observed that ITC treatment of A. brassicicola disrupted the mitochondrial membrane potential. A similar observation was reported in breast cancer cells exposed to Bz-ITC (Xiao et al., 2006) and mitochondria were found to be the primary targets of ITCs in human bladder cells (Tang and Zhang, 2005). The question of whether the collapse of the mitochondrial membrane potential was caused by mitochondriagenerated ROS has to be raised. In human breast and prostate cancer cells, it was indeed shown that ITC treatment reduced the oxygen consumption rate due to inhibition of complex III activity (Xiao et al., 2008, 2009). Using phosphorescence-quenching oxymetry, we showed here that exposure to a high concentration $(10 \mathrm{mM})$ of Al-ITC also resulted in a significant decrease in the oxygen consumption rate by $A$. brassicicola. This suggested a possible effect on mitochondrial oxidative phosphorylation although inhibition of glycolysis or of the tricarboxylic acid cycle cannot be excluded.

Another mechanism by which ITC might disrupt cell redox homeostasis has been proposed and at least in part involves the glutathione cycle (Brown and Hampton, 2011). It has been suggested that these metabolites exacerbate oxidative stress by causing depletion of intracellular glutathione (Sahu et al., 2009; Wu et al., 2010; Tusskorn et al., 2013). GSH depletion is quite likely due to the inhibition of glutathione reductase ( $\mathrm{Hu}$ et al., 2007) and increased conjugation of glutathione to ITC catalyzed by induced glutathione-S-transferases (Sahu et al., 2009). A similar mechanism has been proposed to explain the cell toxicity of another plant-derived thiol-selective reagent (Gruhlke et al., 2010). In line with this hypothesis, we showed here that the expression of five fungal GSTs was strongly induced after short-term exposure to ITC. However, it has yet to be determined whether these enzymes are all able to catalyze the conjugation of glutathione to ITC.

Irrespective of the mechanism by which ITC exerts its toxicity, exposure to even low concentrations of Al-ITC could thus potentially negatively impact the fungal cell metabolism, but interestingly, A. brassissicola seemed to manage the exposure to the compound (e.g., at $2.5 \mathrm{mM}$ ) since growth was delayed, but then proceed at an almost normal rate. This suggests that moderate concentrations of Al-ITC induce alterations in mitochondria (e.g., complex III inhibition) and/or depletion of intracellular glutathione, which results in increased ROS production. The latter elicits AbHog1- and AbAP1-mediated responses (and possibly others), which reinforce anti-oxidant mechanisms, allowing the energy metabolism to cope with the presence of Al-ITC.

In line with this hypothesis, the ITC-induced overexpression of the majority of the oxidative stress response genes analyzed 


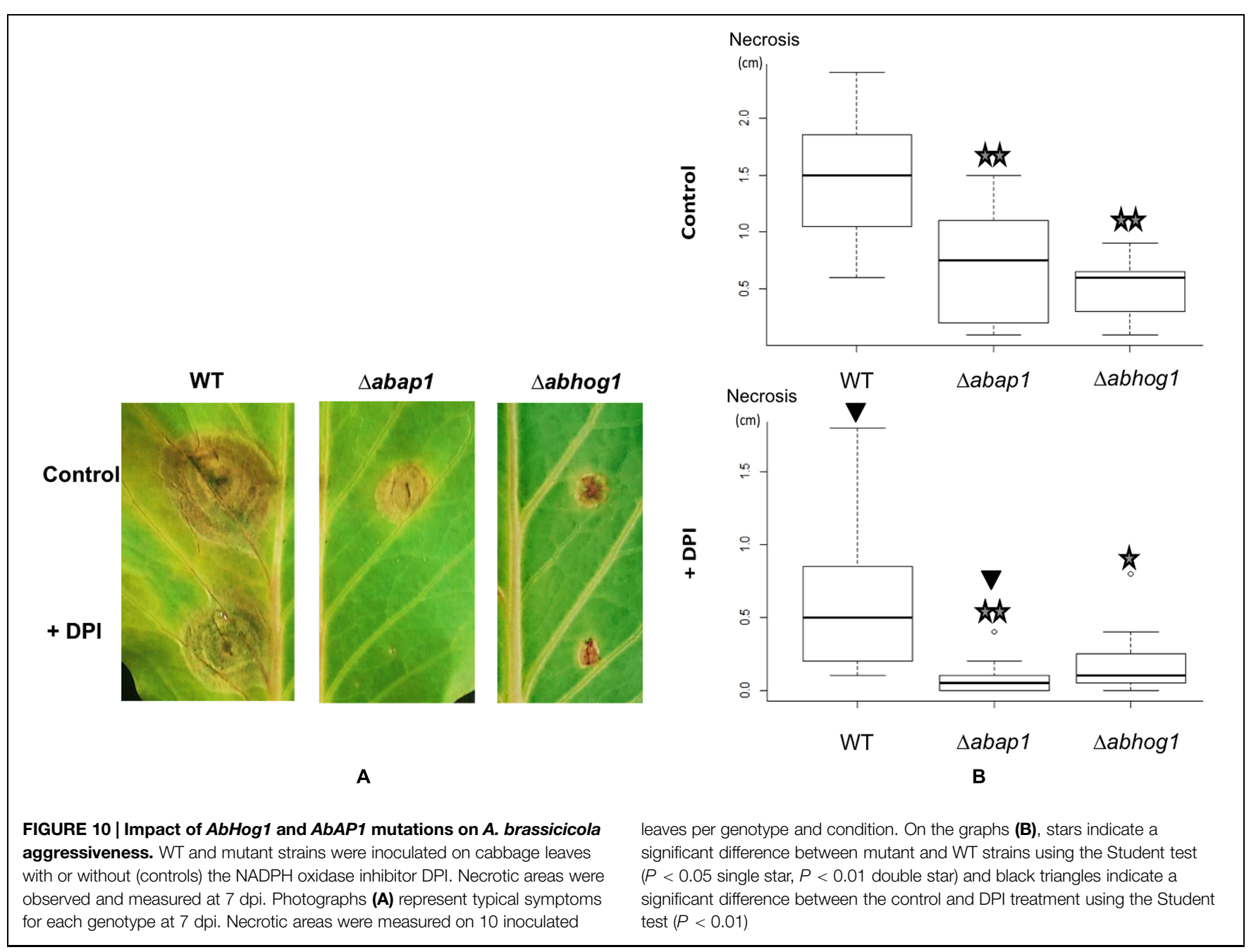

in our study was found to be AP1-dependent. AP1-like TFs have been shown to have crucial roles in the regulation of the oxidative stress responses in yeast and filamentous fungi. These TFs induce, when activated, the expression of many antioxidants and related protein-encoding genes such as genes involved in the thioredoxin and glutathione systems (Temme and Tudzynski, 2009; Takahashi et al., 2010; Guo et al., 2011; Tian et al., 2011). For instance, in line with our findings, among the 12 menadione-induced genes identified as expressed in an AP1dependent manner in Neurospora crassa by Takahashi et al. (2010) four were putative GSTs. Yeast AP1 and other fungal AP1-like proteins characterized so far are B-ZIP TFs whose subcellular localization is under redox control (Kuge et al., 2001; Lev et al., 2005; Yang et al., 2009; Guo et al., 2011). Regulation of the AP1 protein by subcellular localization has been studied in detail in yeast and relies on the reversible binding of an export receptor, CRM1, to the YAP1 nuclear export signal (Kuge et al., 2001). We observed here that the AbAP1-eGFP fusion protein localized inside the nucleus upon exposure to ITC suggesting that AbAP1 also functions as a redox sensor that undergoes rapid activation (i.e., conformational change) due to the ITC-driven cellular redox dysregulation. As expected from this observation, the AbAP1-deficient $A$. brassicicola mutant strain was found to be highly sensitive to oxidative stress caused by $\mathrm{H}_{2} \mathrm{O}_{2}$, menadione and ITCs.

In mammals, ITCs have been repeatedly reported to activate parallel MAP kinase cascades, e.g., extracellular signal-regulated kinase (ERK), c-Jun N-terminal kinase (JNK) and p38 (Juge et al., 2007; Sahu et al., 2009; Geng et al., 2011; Liu et al., 2012). The MAP kinase Hog1 is the yeast homolog of p38 (Sheikh-Hamad and Gustin, 2004) and is a crucial participant in osmotic stress but has limited functions in the oxidative-stress response (Toone and Jones, 1998). By contrast, Hog1 homologs in several other fungal species have a pivotal role in the response to oxidant challenge (Moye-Rowley, 2003; Aguirre et al., 2006; Segmüller et al., 2007; Lin and Chung, 2010). Our results show that the phosphorylation status of AbHog1 changed soon after exposure to ITC and that the phosphorylated form of the protein transiently accumulated in A. brassicicola. In parallel we demonstrated that the MAP kinase migrated into the nucleus in fungal cells challenged with ITC. Taken together these observations strongly suggest that the MAP kinase AbHogl is activated in response to ITC exposure. As the $\Delta a b h o g 1$ mutant strains were found to be hypersensitive to oxidative stress and ITC, it could be hypothesized that the 
nuclear form of the MAP kinase controls the expression of a set of oxidative response genes. However, none of the ITC-induced oxidative response genes selected in our study were found to require Hogl for induction (data not shown). In line with this observation, Enjalbert et al. (2006) showed that although inactivation of Hog1 resulted in high sensitivity toward oxidative stress in Candida albicans, only 46 of the 246 genes induced in response to $\mathrm{H}_{2} \mathrm{O}_{2}$ displayed $\mathrm{Hog} 1$ dependency for their induction and none of them encoded proteins with obvious antioxidant function. More recently, Heller et al. (2012) showed that the majority of gene regulated by BcSak1, the Hog1 homolog in $B$. cinerea, are not involved in the oxidative stress response. In $C$. albicans, it was also shown that mutants that lack the Hog1 MAP kinase had an enhanced basal respiratory rate, higher levels of intracellular ROS and increased sensitivity to inhibitors of the respiratory chain (Alonso-Monge et al., 2009). If such link between the Hog1 MAP kinase pathway and respiratory metabolism also exists in A. brassicicola, this could at least partly explain the high sensitivity of the AbHog1-deficient mutant to ITCs.

The importance of glucosinolate and glucosinolatebreakdown products in the interaction between Brassicaceae and fungal pathogens has long been a matter of debate. While some reports suggest that glucosinolate-breakdown products actively participate in plant defense (Tierens et al., 2001; Stotz et al., 2011), a correlation between glucosinolate content and resistance has not always been demonstrated (Kliebenstein et al., 2002). These apparent contradictions might reflect different lifestyles, i.e., biotrophic versus necrotrophic (Sanchez-Vallet et al., 2010), and host-ranges, i.e., broad-spectrum versus Brassicaceae-specialist (Buxdorf et al., 2013) of the pathogens as well as the variety of GLS and glucosinolate-breakdown products of the host plants. For instance, in addition to sinigrin, the precursor of Al-ITC, fifteen other GLS (aliphatic, aromatic and indolic) were identified in seeds of various Brassica species with high inter-specific or even inter-cultivar variability (Bennett et al., 2004). Our previous observations (Sellam et al., 2007a) and the data reported here demonstrated that WT strains of the Brassicaceae-specific fungus $A$. brassicicola were only slightly sensitive to various ITCs with in vitro $\mathrm{IC}_{50}$ in the millimolar range, i.e., 100- to 1000-fold higher than those measured for human bacterial pathogen (Dufour et al., 2012) and mammalian cancer cells (Liu et al., 2013), respectively. Although such high concentrations of glucosinolate-breakdown products are likely to accumulate in some parts (e.g., midvein and leaf periphery) of colonized plant tissues (Shroff et al., 2008), the ability of A. brassicicola to develop successful infections suggests that this fungus has evolved efficient mechanisms to overcome their toxicity. In the present study, we hypothesized that enhanced expression of oxidative response genes could represent a key mechanism for fungal protection against glucosinolate-breakdown products. In planta oxidative stress may originate from reactions other than the release of ITCs during infection, and the generation of ROS catalyzed by membrane-bound NADPH oxidases (Lamb and Dixon, 1997) is regarded as one of the first responses to fungal invasion (Mellersh et al., 2002). Plant inoculations were thus performed in the presence or absence of an NADPH oxidase inhibitor (diphenylene iodonium). When leaves were inoculated in the presence of the NADPH oxidase inhibitor, smaller lesions were observed irrespective of the fungal genotype. This observation is in line with previous reports showing that the oxidative burst produced by the host may facilitate colonization by necrotrophic fungi (Govrin and Levine, 2000; Williams et al., 2011; Singh et al., 2012). It is also in agreement with Pogany et al. (2009) who reported slower tissue colonization by $A$. brassicicola of the $A$. thaliana NADPH oxidase mutant AtrbohD compared to the WT ecotype. The reduced size of lesions on DPI-treated samples may also be explained by an inhibition of fungal NADPH oxidases that have been shown to be essential for fungal differentiation processes that are necessary for virulence (Heller and Tudzynski, 2011). Irrespective of the conditions used, $\Delta a b a p 1$ and the $\Delta a b h o g 1$ mutants produced significantly smaller lesions than the WT strain when inoculated on B. oleracea leaves. Although these observations indicate that ITCs are important in the defense of Brassica plants against A. brassicicola, it should be remembered that besides its role in the response to oxidative stress, $\mathrm{AbHog} 1$ has been shown to play a central role in the response to many other stresses, including phytoalexin-induced stress (Joubert et al., 2011). Similarly, although the expression of several oxidative response genes was found to be dependent of AbAP1, it has been shown that AP1 homologs may also regulate the expression of genes directly involved in pathogenicity (Guo et al., 2011). Consequently, the failure of the $\Delta a b h o g 1$ and $\Delta a b a p 1$ mutants to colonize $B$. oleracea leaves may not only be linked to their increased ITC sensitivity.

Recently, by comparing the behavior of the broadspectrum pathogen Botrytis cinerea and the Brassica specialist A. brassicicola on different Arabidopsis thaliana genotypes, Buxdorf et al. (2013) suggested that A. brassicicola has adapted to the presence of GLS and can cope with glucosinolatehydrolysis products more efficiently than the generalist $B$. cinerea which is more sensitive to these phytochemicals. In line with this, our results strongly suggest that the robust protection response against ICT-derived oxidative stress might be a key adaptation mechanism for successful infection of host plants by Brassicaceae-specialist necrotrophs like A. brassicicola. An important next step is thus to compare the cell responses to ITC in Brassica specialists like A. brassicicola and generalists like B. cinerea.

\section{Author Contributions}

BC and GN contributed equally to this work. BC carried out the molecular genetic experiments, pathological tests and confocal microscopy examinations. GN and DM performed the oxygen consumption rate assays. $\mathrm{CB}$ and $\mathrm{GN}$ were involved in the phenotyping of the Alternaria strains and gene expression analyses. CC analyzed AbHog1 phosphorylation state. JD, SP, and ED were involved in the construction and phenotyping of strains expressing gfp and m-cherry. BI characterized ROS accumulation with the fluorescent probes. PS and TG conceived the study. All authors participated in the design of the experiments as well as 
analysis of the results. All authors participated in the editing and approved its final version.

\section{Acknowledgments}

We are grateful to members of the INEM, COMIC, and IMAC facilities for providing plants, preserving fungal strains and for assistance during microscopic observations, respectively. This work was supported by post-doctoral fellowships (JD and $\mathrm{CAB}$ ) provided by the CADRES and the University of Angers,

\section{References}

Aguirre, J., Hansberg, W., and Navarro, R. (2006). Fungal responses to reactive oxygen species. Med. Mycol. S44, 101-107. doi: 10.1080/136937806009 00080

Ahuja, I., Kissen, R., and Bones, A. M. (2012). Phytoalexins in defense against pathogens. Trends Plant Sci. 17, 73-90. doi: 10.1016/j.tplants.2011.11.002

Alonso-Monge, R., Carvaihlo, S., Nombela, C., Rial, E., and Pla, J. (2009). The Hog1 MAP kinase controls respiratory metabolism in the fungal pathogen Candida albicans. Microbiology 155, 413-442. doi: 10.1099/mic.0.023309-0

Asano, Y., Hagiwara, D., Yamashino, T., and Mizuno, T. (2007). Characterization of the bZiptype transcription factor NapA with reference to oxidative stress response in Aspergillus nidulans. Biosci. Biotechnol. Biochem. 71, 1800-1803. doi: 10.1271/bbb.70133

Batova, M., Klobunikova, V., Oblasova, Z., Gragan, J., Zahradnik, P., Hapala, I., et al. (2010). Chemogenomic and transcriptome analysis identifies mode of action of the chemosensitizing agent CTBT (7-chlorotetrazolo[5,1c]benzo[1,2,4] triazine). BMC Genomics 11:153. doi: 10.1186/1471-2164-11-153

Bednarek, P., Pislewska-Bednarek, M., Svatos, A., Schneider, B., Doubsky, J., Mansurova, M., et al. (2009). A glucosinolate metabolism pathway in living plant cells mediates broad-spectrum antifungal defense. Science 323, 101-106. doi: 10.1126/science.1163732

Bennett, R. N., Mellon, F. A., and Kroon, P. A. (2004). Screening crucifer seeds as source of specific intact glucosinolates using ion-pair high-performance liquid chromatography negative ion electrospray mass spectrometry. J. Agric. Food Chem. 52, 428-438. doi: 10.1021/jf030530p

Boreddy, S. R., Sahu, R. P., and Srivastava, S. K. (2011). Benzyl isothiocyanate suppresses pancreatic tumor angiogenesis and invasion by inhibiting HIFalpha/VEGF/Rho-GTPases: pivotal role of STAT-3. PLoS ONE 6:e25799. doi: 10.1371/journal.pone.0025799

Brown, K. K., and Hampton, M. B. (2011). Biological targets of isothiocyanates. Biochim. Biophys. Acta 1810, 888-894. doi: 10.1016/j.bbagen.2011.06.004

Buxdorf, K., Yaffe, H., Barda, O., and Levy, M. (2013). The effects of glucosinolates and their breakdown products on necrotrophic fungi. PLOS ONE 8:e70771. doi: 10.1371/journal.pone.0070771

Cho, Y., Davis, J. W., Kim, K. H., Wang, J., Sun, Q. H., Cramer, R. A. Jr., et al. (2006). A high throughput targeted gene disruption method for Alternaria brassicicola functional genomics using linear minimal element (LME) constructs. Mol. Plant Microbe Interact. 19, 7-15. doi: 10.1094/MPMI19-0007

Clay, N. K., Adio, A. M., Denoux, C., Jander, G., and Ausubel, F. M. (2009). Glucosinolate metabolites required for an Arabidopsis innate immune response. Science 323, 95-101. doi: 10.1126/science.1164627

Cuddihy, S. L., Brown, K. K., Thomson, S. J., and Hampton, M. B. (2008). Induction of apoptosis by phenethyl isothiocyanate in cells overexpressing Bcl-XL. Cancer Lett. 271, 215-221. doi: 10.1016/j.canlet.2008.06.002

Curtis, H., Noll, U., Störmann, J., and Slusarenko, A. J. (2004). Broad-spectrum activity of the volatile phytoanticipin allicin in extracts of garlic (Allium sativum L.) against plant pathogenic bacteria, fungi and Oomycetes. Physiol. Mol. Plant Pathol. 65, 79-89. doi: 10.1016/j.pmpp.2004.11.006

Dongo, A., Bataillé-Simoneau, N., Campion, C., Guillemette, T., Hamon, B., Iacomi-Vasilescu, et al. (2009). The group III two-component histidine kinase of filamentous fungi is involved in the fungicidal activity of the bacterial polyketide respectively. We wish to thank David Manley for editing the manuscript.

\section{Supplementary Material}

The Supplementary Material for this article can be found online at: http://journal.frontiersin.org/article/10.3389/fpls. 2015.00414/abstract

Figure S1 | Amino-acid sequence of AbAp1.

ambruticin. Appl. Environ. Microbiol. 75, 127-134. doi: 10.1128/AEM. 00993-08

Dufour, V., Alazzam, B., Ermel, G., Thepaut, M., Rossero, A., Tresse, O., et al. (2012). Antimicrobial activities of isothiocyanates against Campylobacter jejuni isolates. Front. Cell Infect. Microbiol. 2:53. doi: 10.3389/fcimb.2012.00053

Enjalbert, B., Smith, D. A., Cornell, M. J., Alam, I., Nicholls, S., Brown, A. J., et al. (2006). Role of the Hogl stress activated protein kinase in the global transcriptional response to stress in the fungal pathogen Candida albicans. Mol. Biol. Cell 17, 1018-1032. doi: 10.1091/mbc.E05-06-0501

Fahey, J. W., Zalcmann, A. T., and Talalay, P. (2001). The chemical diversity and distribution of glucosinolates and isothiocyanates among plants. Phytochemistry 56, 5-51. doi: 10.1016/S0031-9422(00)00316-2

Geng, F., Tang, L., Li, Y., Yang, L., Choi, K. S., Kazim, A. L., et al. (2011). Allyl isothiocyanate arrests cancer cells in mitosis, and mitotic arrest in turn leads to apoptosis via BCL-2 phosphorylation. J. Biol. Chem. 286, 32259-32267. doi: 10.1074/jbc.M111.278127

Govrin, E. M., and Levine, A. (2000). The hypersensitive response facilitates plant infection by the necrotrophic pathogen Botrytis cinerea. Curr. Biol. 10, 751-757. doi: 10.1016/S0960-9822(00)00560-1

Gruhlke, M. C. H., Portz, D., Stitz, M., Anwar, A., Schneider, T., Jacob, C., et al. (2010). Allicin disrupts the cell's electrochemical potential and induces apoptosis in yeast. Free Radic. Biol. Med. 49, 1916-1924. doi: 10.1016/j.freeradbiomed.2010.09.019

Guo, M., Chen, Y., Du, Y., Dong, Y., Guo, W., Zhai, S., et al. (2011). The bZIP transcription factor MoAP1 mediates the oxidative stress response and is critical for pathogenicity of the rice blast fungus Magnaporthe oryzae. PLoS Pathog. 7:e1001302. doi: 10.1371/journal.ppat.1001302

Hammerschmidt, R. (1999). Phytoalexins: what have we learned after 60 years? Annu. Rev. Phytopathol. 37, 285-306. doi: 10.1146/annurev.phyto.37.1.285

Heller, J., Ruhnke, N., Espino, J. J., Massaroli, M., Collado, I. G., and Tudzynski, P. (2012). The mitogen-activated protein kinase BcSak1 of Botrytis cinerea is required for pathogenic development and has broad regulatory functions beyond stress response. Mol. Plant Microbe Interact. 25, 802-816. doi: 10.1094/MPMI-11-11-0299

Heller, J., and Tudzynski, P. (2011). Reactive oxygen species in phytopathogenic fungi: signaling, development, and disease. Annu. Rev. Phytopathol. 49, 369390. doi: 10.1146/annurev-phyto-072910-095355

Hu, Y., Urig, S., Koncarevic, S., Wu, X., Fischer, M., Rahlfs, S., et al. (2007). Glutathione- and thioredoxin-related enzymes are modulated by sulfur-containing chemopreventive agents. Biol. Chem. 388, 1069-1081. doi: 10.1515/BC.2007.135

Joubert, A., Bataille-Simoneau, N., Campion, C., Guillemette, T., Hudhomme, P., Iacomi-Vasilescu, B., et al. (2011). Cell wall integrity and high osmolarity glycerol pathways are required for adaptation of Alternaria brassicicola to cell wall stress caused by brassicaceous indolic phytoalexins. Cell. Microbiol. 13, 62-80. doi: 10.1111/j.1462-5822.2010.01520.x

Joubert, A., Calmes, B., Berruyer, R., Pihet, M., Bouchara, J. P., Simoneau, P., et al. (2010). Laser nephelometry applied in an automated microplate system to study filamentous fungus growth. BioTechniques 48, 399-404. doi: 10.2144/0001 13399

Juge, N., Mithen, R. F., and Traka, M. (2007). Molecular basis for chemoprevention by sulforaphane: a comprehensive review. Cell. Mol. Life Sci. 64, 1105-1127. doi: 10.1007/s00018-007-6484-5 
Khang, C. H., Berruyer, R., Giraldo, M. C., Kankanala, P., Park, S. Y., Czymmek, K., et al. (2010). Translocation of Magnaporthe oryzae effectors into rice cells and their subsequent cell-to-cell movement. Plant Cell 22, 1388-1403. doi: 10.1105/tpc.109.069666

Kliebenstein, D., Pedersen, D., Barker, B., and Mitchell-Olds, T. (2002). Comparative analysis of quantitative trait loci controlling glucosinolates, myrosinase and insect resistance in Arabidopsis thaliana. Genetics 161, 325-332.

Kuge, S., Arita, M., Murayama, A., Maeta, K., Izawa, S., Inoue, Y., et al. (2001). Regulation of the yeast Yap1p nuclear export signal is mediated by redox signalinduced reversible disulfide bond formation. Mol. Cell. Biol. 21, 6139-6150. doi: 10.1128/MCB.21.18.6139-6150.2001

Lamb, C., and Dixon, R. A. (1997). The oxidative burst in plant disease resistance. Annu. Rev. Plant Biol. 48, 251-275. doi: 10.1146/annurev.arplant.48.1.251

Lambrix, V., Reichelt, M., Mitchell-Olds, T., Kliebenstein, D. J., and Gershenzon, J. (2001). The Arabidopsis epithiospecifier protein promotes the hydrolysis of glucosinolates to nitriles and influences Trichoplusia ni herbivory. Plant Cell 13, 2793-2807. doi: 10.1105/tpc.13.12.2793

Lecomte, M., Berruyer, R., Hamama, L., Boedo, C., Hudhomme, P., Bersihand, S., et al. (2012). Inhibitory effects of the carrot metabolites 6-methoxymellein and falcarindiol on development of the fungal leaf blight pathogen Alternaria dauci. Physiol. Mol. Plant Pathol. 80, 58-67. doi: 10.1016/j.pmpp.2012.10.002

Lee, J., Godon, C., Lagniel, G., Spector, D., Garin, J., Labarre, J., et al. (1999). Yap1 and Skn7 control two specialized oxidative stress response regulons in yeast. J. Biol. Chem. 274, 16040-16046. doi: 10.1074/jbc.274.23.16040

Lev, S., Hadar, R., Amedeo, P., Baker, S. E., Yoder, O. C., and Horwitz, B. A. (2005). Activation of an AP1-like transcription factor of the maize pathogen Cochliobolus heterostrophus in response to oxidative stress and plant signals. Eukaryot. Cell 4, 443-454. doi: 10.1128/EC.4.2.443-454.2005

Lin, C. H., and Chung K. R. (2010). Specialized and shared functions of the histidine kinase- and HOG1 MAP kinase-mediated signaling pathways in Alternaria alternata, a filamentous fungal pathogen of citrus. Fungal Genet. Biol. 47, 818-827. doi: 10.1016/j.fgb.2010.06.009

Liu, B. N., Yan, H. Q., Wu, X., Pan, Z. H., Zhu, Y., Meng, Z.W., et al. (2012). Apoptosis induced by benzyl isothiocyanate in gefitinib-resistant lung cancer cells is associated with Akt/MAPK pathways and generation of reactive oxygen species. Cell. Biochem. Biophys. 66, 81-92. doi: 10.1007/s12013-0129456-9

Liu, K., Cang, S., Ma, Y., and Chiao, J. W. (2013). Synergistic effect of paclitaxel and epigenetic agent phenethyl isothiocyanate on growth inhibition, cell cycle arrest and apoptosis in breast cancer cells. Cancer Cell. Int. 13, 10. doi: 10.1186/14752867-13-10

Lorang, J. M., Tuori, R. P., Martinez, J. P., Sawyer, T. L., Redman, R. S., Rollins, J. A., et al. (2001). Green fluorescent protein is lighting up fungal biology. Appl. Environ. Microbiol. 67, 1987-1994. doi: 10.1128/AEM.67.5.1987-1994.2001

Manici, L. M., Lazzeri, L., and Palmieri, S. (1997). In vitro fungitoxic activity of some glucosinolates and their enzyme-derived products toward plant pathogenic fungi. J. Agri. Food Chem. 45, 2768-2773. doi: 10.1021/jf9608635

Mellersh, D. G., Foulds, I. V., Higgins, V. J., and Heath, M. C. (2002). H2O2 plays different roles in determining penetration failure in three diverse plant-fungal interactions. Plant J. 29, 257-268. doi: 10.1046/j.0960-7412.2001.01215.x

Mi, L., Xiao, Z., Hood, B. L., Dakshanamurthy, S., Wang, X., Govind, S., et al. (2008). Covalent binding to tubulin by isothiocyanates. A mechanism of cell growth arrest and apoptosis. J. Biol. Chem. 283, 22136-22146. doi: 10.1074/jbc.M802330200

Montibus, M., Ducos, C., Bonnin-Verdal, M. N., Bormann, J., Ponts, N., RichardForget, F., et al. (2013). The bZIP transcription factor Fgap1 mediates oxidative stress response and trichothecene biosynthesis but not virulence in Fusarium graminearum. PLoS ONE 8:e83377. doi: 10.1371/journal.pone.0083377

Morrissey, J. P., and Osbourn, A. E. (1999). Fungal resistance to plant antibiotics as a mechanism of pathogenesis. Microbiol. Mol. Biol. Rev. 63, 708-724.

Moye-Rowley, S. W. (2003). Regulation of the transcriptional response to oxidative stress in fungi: similarities and differences. Eukaryot. Cell. 2, 381-389. doi: 10.1128/EC.2.3.381-389.2003

Navarro, S. L., Li, F., and Lampe, J. W. (2011). Mechanisms of action of isothiocyanates in cancer chemoprevention: an update. Food Funct. 2, 579-587. doi: $10.1039 / \mathrm{c} 1$ fo $10114 \mathrm{e}$

Osbourn, A. E. (1996). Preformed antimicrobial compounds and plant defence against fungal attack. Plant Cell 8, 1821-1831. doi: 10.1105/tpc.8.10.1821
Pochon, S., Simoneau, P., Pigné, S., Balidas, S., Bataillé-Simoneau, N., Campion, C., et al. (2013). Dehydrin-like proteins in the necrotrophic fungus Alternaria brassicicola have a role in plant pathogenesis and stress response. PLoS ONE 8:e75143. doi: 10.1371/journal.pone.0075143

Pogany, M., von Rad, U., Grun, S., Dongo, A., Pintye, A., Simoneau, P., et al. (2009). Dual roles of reactive oxygen species and NADPH oxidase RBOHD in an Arabidopsis- Alternaria pathosystem. Plant Physiol. 151, 1459-1475. doi: 10.1104/pp.109.141994

Reiser, V., Ruis, H., and Ammerer, G. (1999). Kinase activity-dependent nuclear export opposes stress-induced nuclear accumulation and retention of Hog mitogen-activated protein kinase in the budding yeast Saccharomyces cerevisiae. Mol. Biol. Cell. 10, 1147-1161. doi: 10.1091/mbc.10.4.1147

Sahu, R. P., Zhang, R., Batra, S., Shi, Y., and Srivastava, S. K. (2009). Benzyl isothiocyanate-mediated generation of reactive oxygen species causes cell cycle arrest and induces apoptosis via activation of MAPK in human pancreatic cancer cells. Carcinogenesis 30, 1744-1753. doi: 10.1093/carcin/ bgp 157

Sanchez-Vallet, A., Ramos, B., Bednarek, P., Lopez, G., PislewskaBednarek, M., Schulze-Lefert, P., et al. (2010). Tryptophan-derived secondary metabolites in Arabidopsis thaliana confer non-host resistance to necrotrophic Plectosphaerella cucumerina fungi. Plant J. 63, 115-127. doi: 10.1111/j.1365-313x.2010.04224.x

Scalliet, G., Bowler, J., Luksch, T., Kirchhofer-Allan, L., Steinhauer, D., Ward, K., et al. (2012). Mutagenesis and functional studies with succinate dehydrogenase inhibitors in the wheat pathogen Mycosphaerella graminicola. PLoS ONE 7:e35429. doi: 10.1371/journal.pone.0035429

Segmüller, N., Ellendorf, U., Tudzynski, B., and Tudzynski, P. (2007). BcSak1, a stress-activated mitogen-activated protein kinase, is involved in vegetative differentiation and pathogenicity in Botrytis cinerea. Eukaryot. Cell. 6, 211-221. doi: 10.1128/EC.00153-06

Sellam, A., Iacomi-Vasilescu, B., Hudhomme, P., and Simoneau, P. (2007a). In vitro antifungal activity of brassinin, camalexin and two isothiocyanates against the crucifer pathogens Alternaria brassicicola and Alternaria brassicae. Plant Pathol. 56, 296-301. doi: 10.1111/j.1365-3059.2006.01497.x

Sellam, A., Dongo, A., Guillemette, T., Hudhomme, P., and Simoneau, P. (2007b). Transcriptional responses to exposure to the brassicaceous defence metabolites camalexin and allyl-isothiocyanate in the necrotrophic fungus Alternaria brassicicola. Mol. Plant Pathol. 8, 195-208. doi: 10.1111/j.13643703.2007.00387.x

Sheikh-Hamad, D., and Gustin, M. C. (2004). MAP kinases and the adaptive response to hypertonicity: functional preservation from yeast to mammals. Am. J. Physiol. Renal Physiol. 287, F1102-F1110. doi: 10.1152/ajprenal.0022 5.2004

Shroff, R., Vergara, F., Muck, A., Svatos, A., and Gershenzon, J. (2008). Nonuniform distribution of glucosinolates in Arabidopsis thaliana leaves has important consequences for plant defense. Proc. Natl. Acad. Sci. U.S.A. 105, 6196-6201. doi: 10.1073/pnas.0711730105

Singh, K., Nizam, S., Sinha, M., and Verma, P. K. (2012). Comparative transcriptome analysis of the necrotrophic fungus Ascochyta rabiei during oxidative stress: insight for fungal survival in the host plant. PLoS ONE 7:e33128. doi: 10.1371/journal.pone.0033128

Slusarenko, A. J., Patel, A., and Portz, D. (2008). Control of plant diseases by natural products: allicin from garlic as a case study. Eur. J. Plant Pathol. 121, 313-322. doi: 10.1007/s10658-007-9232-7

Smolinska, U., Mora, M. J., Knudsen, G. R., and James, R. L. (2003). Isothiocyanates produced by Brassicaceae species as inhibitors of Fusarium oxysporum. Plant Dis. 87, 407-412. doi: 10.1094/PDIS.2003.87.4.407

Stotz, H. U., Sawada, Y., Shimada, Y., Hirai, M. Y., Sasaki, E., Krischke, M., et al. (2011). Role of camalexin, indole glucosinolates, and side chain modification of glucosinolatederived isothiocyanates in defense of Arabidopsis against Sclerotinia sclerotiorum. Plant J. 67, 81-93. doi: 10.1111/j.1365313X.2011.04578.x

Sweigard, J. A., Carroll, A. M., Kang, S., Farrall, L., Chumley, F. G., and Valent, B. (1995). Identification, cloning, and characterization of PWL2, a gene for host species specificity in the rice blast fungus. Plant Cell 7, 1221-1233. doi: 10.1105/tpc.7.8.1221

Takahashi, M., Yamashita, K., Shiozawa, A., Ichiishi, A., Fukumori, F., and Fujimura, M. (2010). An AP-1-like transcription factor, NAP-1, regulates 
expression of the glutathione S-transferase and NADH: flavin oxidoreductase genes in Neurospora crassa. Biosci. Biotechnol. Biochem. 74, 746-752. doi: $10.1271 /$ bbb. 90790

Tang, L., and Zhang, Y. (2005). Mitochondria are the primary target in isothiocyanate induced apoptosis in human bladder cancer cells. Mol. Cancer Ther. 5, 1250-1259. doi: 10.1158/1535-7163.MCT-05-0041

Temme, N., and Tudzynski, P. (2009). Does Botrytis cinerea ignore H2O2induced oxidative stress during infection? Characterization of Botrytis activator protein 1. Mol. Plant Microbe Interact. 22, 987-998. doi: 10.1094/MPMI-22-80987

Tian, C., Li, J., and Glass, N. L. (2011). Exploring the bZIP transcription factor regulatory network in Neurospora crassa. Microbiology 157, 747-759. doi: 10.1099/mic.0.045468-0

Tierens, K., Thomma, B. P. H., Brouwer, M., Schmidt, J., Kistner, K., Porzel, A., et al. (2001). Study of the role of antimicrobial glucosinolate-derived isothiocyanates in resistance of Arabidopsis to microbial pathogens. Plant Physiol. 125, 16881699. doi: $10.1104 /$ pp. 125.4 .1688

Toone, W. M., and Jones, N. (1998). Stress-activated signalling pathways in yeast. Genes Cells 3, 485-498. doi: 10.1046/j.1365-2443.1998.00211.x

Tusskorn, O., Senggunprai, L., Prawan, A., Kokungviriyapan, U., and Kukongviriyapan, V. (2013). Phenethyl isothiocyanate induces calcium mobilization and mitochondrial cell death pathway in cholangiocarcinoma KKU-M214 cells. BMC Cancer 13:571. doi: 10.1186/1471-240713-571

Williams, B., Kabbage, M., Kim, H. J., Britt, R., and Dickman, M. B. (2011). Tipping the balance: Sclerotinia sclerotiorum secreted oxalic acid suppresses host defenses by manipulating the host redox environment. PLoS Pathog. 7:e1002107. doi: 10.1371/journal.ppat.1002107

Winer, J., Jung, C. K., Shackel, I., and Williams, P. M. (1999). Development and validation of real-time quantitative reverse transcriptase-polymerase chain reaction for monitoring gene expression in cardiac myocytes in vitro. Anal. Biochem. 270, 41-49. doi: 10.1006/abio.1999.4085

Wu, X., Zhu, Y., Yan, H., Liu, B., Li, Y., Zhou, Q., et al. (2010). Isothiocyanates induce oxidative stress and suppress the metastasis potential of human nonsmall cell lung cancer cells. BMC Cancer 10:269. doi: 10.1186/1471-240710-269

Xiao, D., Powolny, A. A., Antosiewicz, J., Hahm, E. R., Bommareddy, A., Zeng, Y., et al. (2009). Cellular responses to cancer chemopreventive agent D, L-sulforaphane in human prostate cancer cells are initiated by mitochondrial reactive oxygen species. Pharm. Res. 26, 1729-1738. doi: 10.1007/s11095-0099883-5

Xiao, D., Powolny, A. A., Moura, M. B., Kelley, E. E., Bommareddy, A., Kim, S. H., et al. (2010). Phenethyl isothiocyanate inhibits oxidative phosphorylation to trigger reactive oxygen species-mediated death of human prostate cancer cells. J. Biol. Chem. 285, 26558-26569. doi: 10.1074/jbc.m109.063255

Xiao, D., Powolny, A. A., and Singh, S. V. (2008). Benzyl isothiocyanate targets mitochondrial respiratory chain to trigger reactive oxygen species-dependent apoptosis in human breast cancer cells. J. Biol. Chem. 283, 30151-30163. doi: 10.1074/jbc.M802529200

Xiao, D., Vogel, V., and Singh, S. V. (2006). Benzyl isothiocyanate-induced apoptosis in human breast cancer cells is initiated by reactive oxygen species and regulated by Bax and Bak. Mol. Cancer Ther. 5, 2931-2945. doi: 10.1158/1535-7163.MCT-06-0396

Yang, S. L., Lin, C. H., and Ching, K.-R. (2009). Coordinate control of oxidative stress tolerance, vegetative growth, and fungal pathogenicity via the AP1 pathway in the rough lemon pathotype of Alternaria alternata. Physiol. Mol. Plant Pathol. 74, 100-111. doi: 10.1016/j.pmpp.2009.09.007

Yu, J. H., Hamari, Z., Han, K. H., Seo, J. A., Reyes-Dominguez, Y., and Scazzocchio, C. (2004). Double-joint PCR: a PCR-based molecular tool for gene manipulations in filamentous fungi. Fungal Genet. Biol. 41, 973-981. doi: 10.1016/j.fgb.2004.08.001

Zhang, Y. (2010). Allyl isothiocyanate as a cancer chemopreventive phytochemical. Mol. Nutr. Food Res. 54, 127-135. doi: 10.1002/mnfr.200900323

Znaidi, S., Barker, K. S., Weber, S., Alarco, A. M., Lju, T. T., Boucher, G., et al. (2009). Identification of the Candida albicans Caplp regulon. Eukaryot. Cell. 8, 806-820. doi: 10.1128/EC.00002-09

Conflict of Interest Statement: The authors declare that the research was conducted in the absence of any commercial or financial relationships that could be construed as a potential conflict of interest.

Copyright (c) 2015 Calmes, N’Guyen, Dumur, Brisach, Campion, Iacomi, Pigné, Dias, Macherel, Guillemette and Simoneau. This is an open-access article distributed under the terms of the Creative Commons Attribution License (CC BY). The use, distribution or reproduction in other forums is permitted, provided the original author(s) or licensor are credited and that the original publication in this journal is cited, in accordance with accepted academic practice. No use, distribution or reproduction is permitted which does not comply with these terms. 